\title{
Reestruturação do modelo de gestão de cursos na modalidade a distância frente às novas demandas
}

\author{
João Artur de Souza - UFSC - jartur@egc.ufsc.br \\ Gertrudes Aparecida Dandolini - UFSC - gtude@egc.ufsc.br \\ Jairo da Silva Campelo - UFPEL - jcampelo@gmail.com
}

Resumo: Este artigo apresenta a estrutura inicial do Curso de Licenciatura em Matemática a Distância da UFPEL e como planejamos a nova estrutura para atender aos Programas Pró-Licenciatura (Fase II) e Universidade Aberta do Brasil do Ministério da Educação. $O$ sucesso do curso exige um planejamento adequado, uma equipe multidisciplinar competente e sincronizada e uma distribuição de responsabilidades que vão além das necessidades de um curso presencial. Além disto, os conhecimentos da equipe devem ser gerenciados a fim de promover melhores condições ao aprendizado dos alunos.

Palavras-chave: Curso a distância, estrutura organizacional, gestão do conhecimento

\section{Restructuring the management model of e-learning courses in front of new demands}

\begin{abstract}
This article presents de initial structure of e-learning mathematic course at The Federal University of Pelotas (UFPEL) and how we are planning a new form to attend the growing number of counties by Pró-Licenciatura (Phase II) and UAB program of Education and Culture Ministery (MEC). The success of the course requires an adequate planning, a competent synchronized and multidisciplinary team, and a distribution of responsibilities that go beyond the needs of presential course. In addition, knowledge of the team should be management to promote better conditions to the learning of students.
\end{abstract}

Keywords: e-learning course, knowledge management, organizational structure

\section{Introdução}

A Educação a Distância no Brasil está crescendo muito rapidamente no nível de Ensino Superior. Segundo estatísticas da ABED $^{1}$, de 2005 para 2006 houve um crescimento de 91\% nos Cursos de Graduação e Pós-Graduação. Naturalmente com a ampliação acelerada no número de cursos oferecidos na modalidade de Ensino a Distância e devido aos novos métodos de trabalho, faz-se necessária uma inovação na forma de gerenciar estes cursos. Existem algumas diferenças entres as modalidades de Ensino a Distância e Presencial, principalmente quando se trata de estrutura administrativa. Na Educação a Distância a oferta dos cursos é realizada em Pólos (cidades que sediam os cursos) e geralmente não há a reoferta do mesmo curso no mesmo pólo, em se tratando

\footnotetext{
${ }^{1}$ Anuário Brasileiro Estatístico de Educação Aberta e a Distância
} 
de cursos oferecidos pelas Instituições Federais de Ensino Superior. Assim, a estrutura de um Curso de Graduação a Distância não pode seguir os moldes tradicionais de um Curso de Graduação Presencial, que normalmente por intermédio de diferentes processos de seleção oferecem novas turmas anualmente ou semestralmente (Souza, 2005).

Quanto à Gestão Administrativa de um Curso de Graduação, esta está ligada diretamente à estrutura organizacional da instituição. Para planejar a execução de um curso, desde a sua criação, a instituição proponente deve ter condições de efetivamente promover o oferecimento do mesmo de forma eficiente. Muitas das IFES (Instituição Federal de Ensino Superior) atualmente não dispõem de infra-estrutura física, de pessoal administrativo e professores capacitados para oferecer Cursos de Graduação a Distância. Apesar de as necessidades não serem substanciais, um dos principais entraves é a própria estrutura organizacional das instituições. As IFES precisam desenvolver modificações em sua estrutura administrativa para viabilizar a criação de cursos na modalidade a distância. Os Cursos a Distância devem ter uma dinâmica voltada para motivar o aluno e as avaliações devem ser direcionadas sob dois aspectos: fundamento científico e plano subjetivo dos alunos (Souza et al., 2004).

Segundo Dandolini (2007) pode-se dizer que toda proposta de Curso a Distância das IFES deve focar a formação de profissionais competentes, críticos, engajados na política e que participem ativamente nas suas comunidades. Os cursos devem ter como princípio pedagógico o trabalho do profissional, propondo a articulação entre teoria e prática, a partir da ação-reflexão-ação sobre o planejamento de ações pedagógicas e tecnológicas.

Segundo Bof (2005) os bons sistemas de EAD (Educação a Distância) são compostos por uma série de componentes que devem funcionar integrados. Apresentaremos no decorrer do artigo a evolução do planejamento do Curso de Matemática na modalidade a distância da UFPEL frente às novas demandas oriundas da Universidade Aberta do Brasil (UAB) e do projeto Pró-Licenciatura II, bem como seu sistema de gestão integrado. A estrutura envolve desde a concepção do curso até a sua oferta e expansão. A gestão é apresentada como um sistema complexo, mas que deve ser planejado e executado com o objetivo de ofertar o curso com eficiência global.

\section{Estrutura administrativa do $\mathrm{CLMD}^{2}$ : breve histórico e adaptações}

No momento em que aceitamos o convite da PRG/UFPEL (Pró Reitoria de Graduação/Universidade Federal de Pelotas), para atender a Chamada Pública da FINEP (Financiadora de Estudos e Pesquisa) e em seguida a Chamada Pública da SEED/MEC (Secretaria de Ensino a Distância/Ministério da Educação), que tratava sobre a criação de cursos de licenciatura (graduação) a distância nas IFES, sentimo-nos desafiados a construir um Projeto que atendesse aos anseios da sociedade como um todo.

Levamos em consideração o fato de que a EAD, por ser uma modalidade de ensino emergente, ainda apresentava muita resistência por parte das instituições (principalmente as públicas) e da própria sociedade. Além de toda a preocupação referente à organização do curso, sabíamos que teríamos que enfrentar a resistência de

${ }^{2}$ CLMD - Curso de Licenciatura em Matemática a Distância 
colegas professores de vários setores da universidade e inclusive dos alunos dos cursos presenciais.

Inicialmente pensou-se em uma Estrutura Administrativa (Figura 1) para gerenciar este trabalho tornando viável o oferecimento de um curso de graduação de qualidade e que ainda buscasse romper as barreiras da EAD na UFPEL.

Na UFPEL, o Curso de Licenciatura em Matemática a Distância iniciou suas atividades em 2005 com apenas três pólos (Jaguarão, Canguçu e Turuçú), onde o pólo mais distante fica a $150 \mathrm{~km}$ de Pelotas. Atualmente, por meio dos Projetos Pró-Licenciatura Fase II (modalidade para professores em exercício do magistério que não possuem graduação e trabalham com a disciplina de matemática) e da Universidade Aberta do Brasil, o número de pólos ampliou para 23.

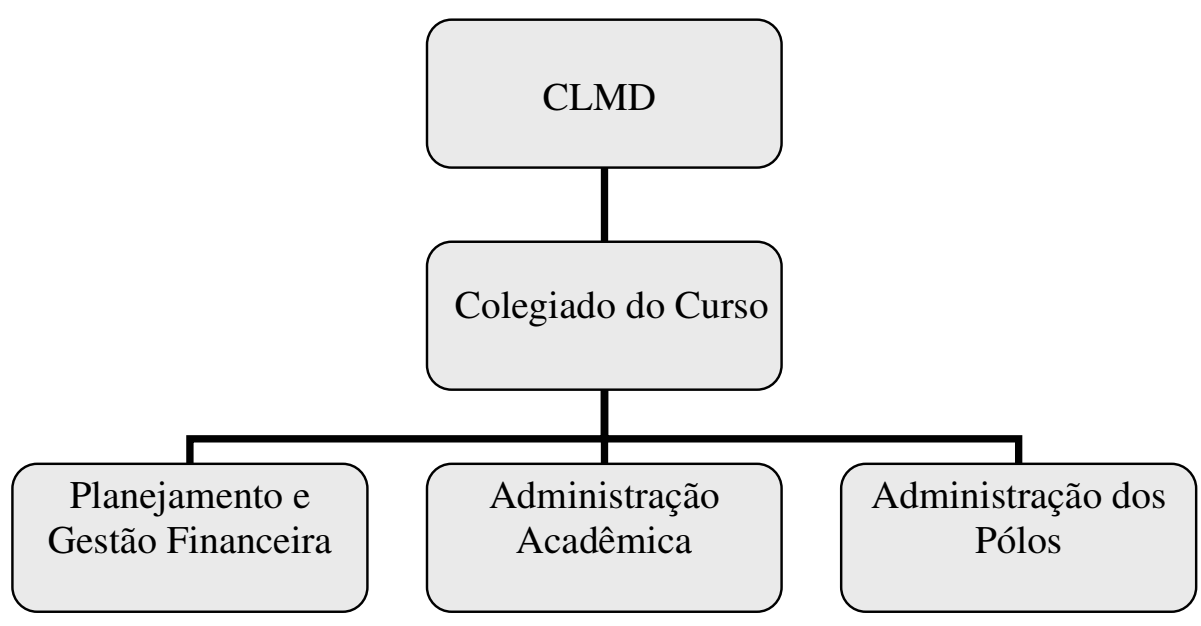

Figura 1: Estrutura Administrativa do CLMD - 2005

\section{A nova estrutura do curso}

A formalização de uma estrutura operacional de um sistema de EAD envolve desde o desenvolvimento da concepção do curso, a produção dos materiais didáticos ou fontes de informação e a definição do sistema de avaliação até o estabelecimento dos mecanismos operacionais de distribuição de matérias, a disponibilização de serviços de apoio à aprendizagem e o estabelecimento de procedimentos acadêmicos (Bof, 2005). Baseados nas mudanças que foram surgindo foi necessário reestruturar o organograma administrativo do CLMD. Na Figura 2 apresentamos esta nova estrutura.

Como os três projetos em execução têm financiamento do MEC/SEED/FNDE ${ }^{3}$ é necessário, além da Administração Pedagógica, uma equipe para atuar na Gestão Financeira do Curso. Também se faz necessário uma equipe para administrar e planejar a execução do curso nos diversos pólos.

As funções ligadas ao Planejamento e à Gestão financeira do CLMD compreendem a elaboração e a execução do orçamento, bem como a administração dos recursos financeiros do projeto, cabendo-lhe, assim, controlar a arrecadação e a aplicação de valores, agendar e autorizar o pagamento de despesas previstas no plano de trabalho,

${ }^{3}$ FNDE - Fundo Nacional de Desenvolvimento da Educação 
tais como contratações de serviços, aquisição de material de consumo, despesas de viagens e outras. Também assessoram o Colegiado nas negociações com as Prefeituras e demais parceiros interessados. O Planejamento é peça chave para a execução de

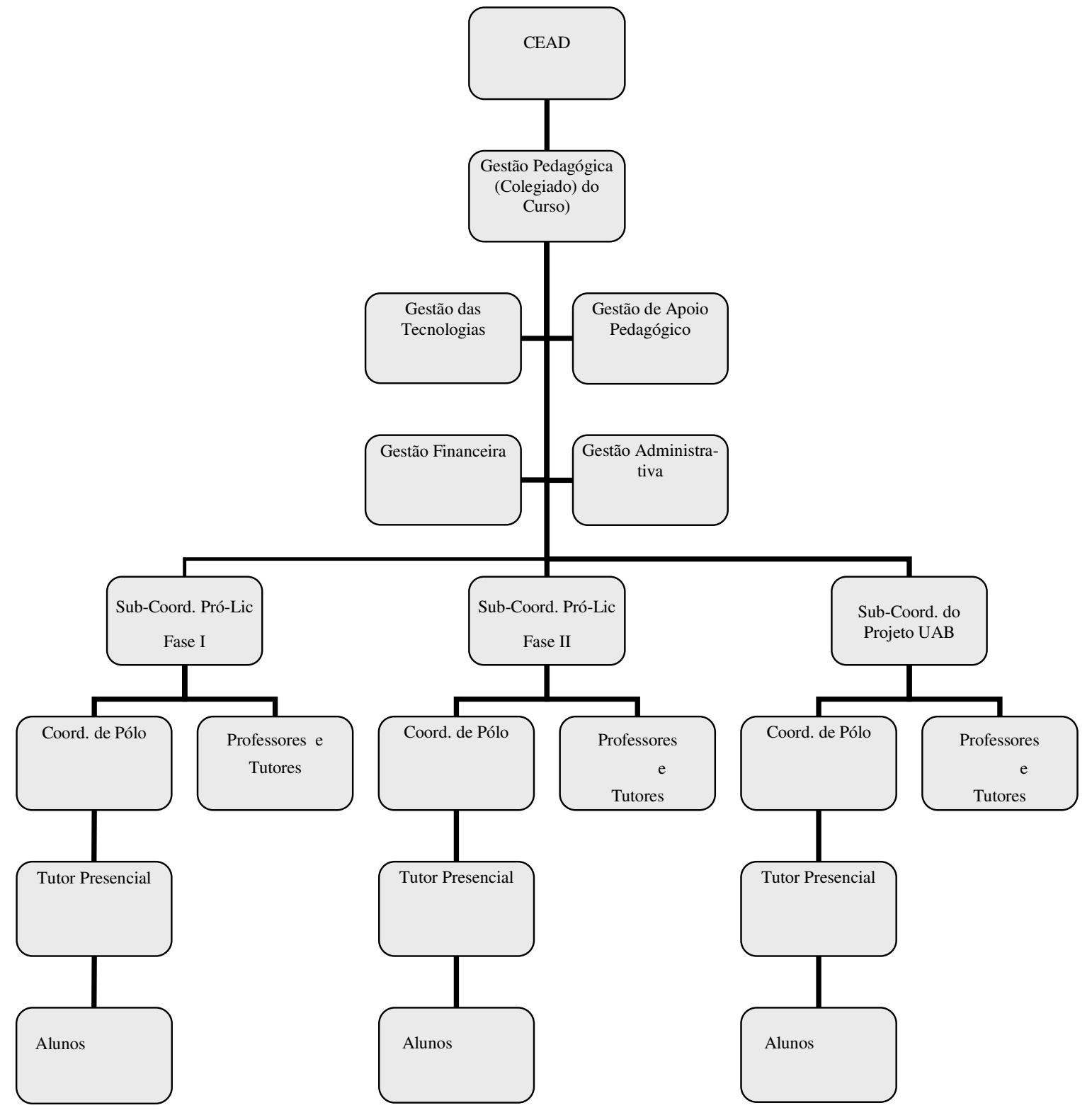

Figura 2 - Estrutura Administrativa do CLMD - 2007

qualquer projeto. Um planejamento bem elaborado e estruturado é que orienta todos os processos na execução de um curso a distância. É por intermédio do planejamento que se monitoram os detalhes dos encontros presenciais, vídeo-aulas, web-conferências e de sua viabilidade financeira. O CLMD se utiliza de planejamento desde a projeção dos custos para o processo seletivo e utilização de internet até a entrega do diploma ao aluno.

A função do Sistema das TICs (Tecnologias de Informação e Comunicação é viabilizar os múltiplos meios de comunicação necessários para o funcionamento do curso. A 
evolução dos meios de comunicação é de grande utilidade na Educação a Distância. A participação do aluno é acompanhada por um processo de avaliação interativa, vinculada ao ambiente virtual de aprendizagem do curso. Esta avaliação permite o monitoramento direto do desempenho do aluno no ambiente por meio da evolução na execução das atividades. O objetivo é identificar possíveis dificuldades no fluxo da "aprendizagem". O ambiente de cada disciplina, além de suas particularidades, constará de exercícios, avaliações, suporte para atendimento a dúvidas via correio eletrônico, momentos de comunicação síncrona e suporte por telefone. Devido à importância que a comunicação e os meios tecnológicos assumem dentro da proposta do curso, torna-se indispensável o trabalho eficiente do Sistema das TICs, a quem caberá dar todo o suporte técnico para que isso seja possível.

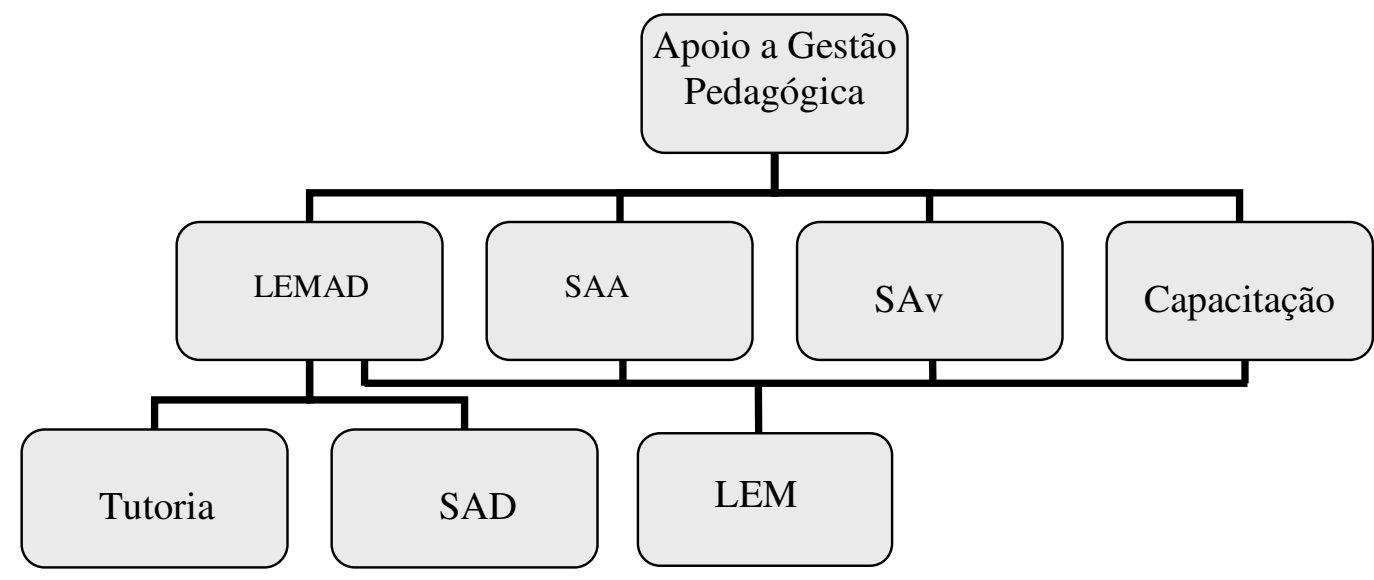

Figura 3 - Estrutura de Apoio Pedagógico do CLMD (Adaptado de Souza, et al., 2007)

No auxílio das responsabilidades do colegiado, a estrutura criada, conforme a Figura 4 atende a uma especificação para o melhor gerenciamento das tarefas e integração das mesmas. A gestão acadêmica conta com o apoio de: Laboratório de Ensino de Matemática a Distância (LEMAD), Sistema de Tutoria, Sala de aula a distância (SAD), Laboratório de Estudos de Matemática (LEM), Sistema de Acompanhamento de Alunos (SAA), Sistema de Avaliação (SAv) e Sistema de Capacitação de Tutores/Alunos.

Tanto os laboratórios como os sistemas, afiliados ao colegiado, buscam em suas atribuições, fornecer os melhores estudos e proposições para que o colegiado possa fazer os momentos de integração, promovendo a execução do curso. Um resultado desta estrutura são os seminários integradores, que buscam em cada semestre promover a inter-relação entre as disciplinas, o processo de avaliação, a regionalidade das turmas, etc., para um eficaz desenvolvimento unificado do curso. Sabe-se que o gerenciamento não pode ser centralizado em uma instância somente, a divisão proposta e já utilizada no curso, permite que as atividades tenham seu percurso autônomo, mas ligado às diretrizes que o colegiado determina (Hardy, 2000).

O Laboratório de Ensino de Matemática a Distância (LEMAD) tem a função de produzir os materiais didáticos necessários à execução do Curso de Licenciatura Matemática a Distância (Vergara Nunes et al., 2005). Ele é constituído de um coordenador, técnicos e alunos estagiários que trabalham juntos com os professores das disciplinas a serem oferecidas. É no Laboratório de Ensino de Matemática a Distância 
que o Curso tem suas atividades mais intensas. É nele que acontecem as discussões que geram a oferta da disciplina, sua metodologia de trabalho e os materiais didáticos que serão adotados para seu melhor funcionamento. A equipe técnica e o coordenador do laboratório, juntamente com os professores pesquisadores e tutores, discutem questões que vão desde os aspectos técnicos como velocidade de processador ou cores de fundo e letras, até as questões didáticas de tempo de concentração ou nível de autonomia que os materiais permitem, passando pela precisão e quantidade de conteúdos a serem inseridos. Trata-se de um trabalho multidisciplinar e desafiador. A diversidade que oferecem as novas tecnologias não permite que se reduzam a um tipo de mídia a serem adotados. É necessário que a política de produção dos materiais esteja relacionada sempre com a potencialidade e habilidades próprias dos professores ou setores que os vão preparar (sempre sob a orientação e responsabilidade do LEMAD). Junto ao LEMAD está a sala de aula a distância (SAD) que propicia a execução de aulas a distância pelos professores responsáveis e o ambiente de professor-tutor. A SAD conta com toda uma infra-estrutura de equipamentos para web-conferência que permite a transmissão das aulas com os mais variados recursos didáticos.

O Sistema de Acompanhamento de Alunos (SAA) é constituído de um Coordenador dos professores pesquisadores, dos professores-tutores e dos monitores das disciplinas do curso. Sua atribuição é de acompanhar, permanentemente a troca de informações entre os envolvidos nas atividades didático-pedagógicas e os processos de ensino e de aprendizagem (Grützmann, 2006). Este trabalho permite a identificação de problemas e a busca de soluções dos mesmos. Desempenha uma função extremamente importante no processo de ensino a distância, pois é por meio deste sistema que se dará o acompanhamento do processo de aprendizagem dos alunos e a verificação de como os alunos estão participando e se envolvendo neste processo, também a identificação do desenvolvimento e das dificuldades dos alunos na aprendizagem. Será, principalmente, por intermédio do SAA que se poderá detectar se os métodos que estão sendo empregados estão sendo eficazes ou não. O contato com os alunos será realizado, principalmente, pelos professores-tutores e pelos monitores. Por isso, esses professores e monitores deverão estar capacitados para exercer seu papel neste processo de ensino. O SAA deverá oferecer cursos de Capacitação ${ }^{4}$ aos professores-tutores e monitores para prepará-los para cumprir com suas responsabilidades.

A principal atribuição do Sistema de Avaliação (SAv) é garantir a qualidade da avaliação permanente da aprendizagem dos alunos e do próprio curso. Como em Souza (2004) a avaliação não é um processo estático, ele é dinâmico e dela depende também a motivação dos alunos.

O Laboratório de Estudos de Matemática (LEM) tem a função de propiciar discussões pedagógicas sobre os materiais e procedimentos didáticos utilizados, propondo novas formas de trabalho a partir do acompanhamento e da análise de todos os trabalhos desenvolvidos no curso. Também é atribuição do LEM projetar, criar, experimentar e avaliar materiais didáticos que serão utilizados pelo curso, particularmente, materiais concretos. O LEM já tem desenvolvidos diversos tipos de materiais concretos para o ensino de matemática nos níveis básicos. Parte desses materiais tem sido utilizada nas disciplinas do curso e também em atividades experimentais em escolas públicas de Pelotas e de cidades vizinhas.

\footnotetext{
${ }^{4}$ Estes cursos de capacitação estarão previstos dentro do cronograma de atividades do Curso.
} 
Conscientes de que um curso a distância está diretamente relacionado com a competência do indivíduo, como participante do processo, optamos por uma proposta que se dirige tanto para a capacitação dos alunos, quanto para a dos professores e tutores. O sistema de Capacitação de Alunos, professores e tutores visa prepará-los para atuar em EAD, seja como aluno ou como professor. A equipe de capacitação oferece dois tipos de curso, um direcionado aos alunos que vão iniciar um curso na modalidade a distância e outro para professores e tutores. O sucesso ou fracasso em um curso a distância depende do grau em que os aprendizes entendam que fazem parte de uma comunidade de aprendizagem, de discurso e de prática. Nesta comunidade de aprendizagem (aprendizagem colaborativa), de discurso e de prática, o estilo de comunicação se relaciona com o modelo de racionalidade comunicativa. É um estilo aberto a desafios, preparado para propiciar condições favoráveis ao diálogo e à negociação de significados, fornecer base às afirmações, construir conceitos bem fundamentados, para desenvolver a reflexão crítica como forma de emancipação. Os cursos de capacitação têm como objetivo levar tutores e professores a compreender os princípios teóricos que orientam uma nova prática pedagógica em cursos a distância, aplicando-os e aprimorando-os para o exercício da tutoria e/ou monitoria em um curso de licenciatura a distância, bem como na sua própria experiência como formador.

Todas essas instâncias devem atuar de modo integrado a fim de propiciar da melhor forma possível a motivação dos alunos e a aprendizagem. Além disso, é de vital importância que professores, tutores da sede e dos pólos trabalhem de forma ativa e motivada, sendo necessária a comunicação e interação entre eles para evitar informações equivocadas.

\section{Gestão do conhecimento}

Para que a operacionalização do curso seja eficiente e abrangente, as tarefas administrativas e pedagógicas devem estar bem definidas e sintonizadas. Com o exposto até agora, podemos concluir que existe uma grande complexidade nessa estrutura e, além disso, essa estrutura exige profissionais de várias áreas. É preciso então que se tenha um profissional para assumir a função de Gestor da equipe que atuará na execução do curso. Este profissional deve ter sensibilidade para gerenciar conhecimentos e habilidades de cada membro da equipe, porque é rotineiro nos depararmos, por exemplo, com educadores identificados mais com a demanda de Produção de Material Didático e outros que são excelentes em ministrar aulas por meio das novas Tecnologias de Informação e Comunicação (TIC). Assim, o gestor da equipe deve saber gerenciar os conhecimentos de sua equipe para que as metas do curso sejam alcançadas.

Por outro lado, uma peça chave nos cursos de EAD é o professor. Esses necessitam de conhecimentos, que vão além do domínio de conteúdos programáticos das disciplinas e conhecimentos didático-pedagógicos. Observe que existe a necessidade de uma evolução nas suas atribuições, ou uma migração das atividades docentes. Esta migração envolve mudanças na ação. Comparando ao que geralmente é atribuído a um "professor tradicional" que, por exemplo, não divide suas atividades com outros colegas, no contexto da EAD, esta possibilidade não existe mais. Nesta nova forma de agir as atividades de um professor vão muito além do domínio de conteúdo. Outros conhecimentos como o domínio tecnológico, o saber trabalhar em equipe, e o saber planejar são cruciais. Desta forma, o professor deve saber gerenciar seus próprios conhecimentos em relação aos aspectos citados acima. 
Esta abordagem está levando a uma gestão do conhecimento, tanto do professor como do coordenador (gestor) que transcendem aos seus domínios específicos. Uma integração de atividades e atitudes que levem ao aprendizado do aluno. A grande questão é perceber a complexidade envolvida em todo o processo e como a evolução deve seguir. $\mathrm{O}$ que se pode esperar são tendências e expectativas, pois não se tem por certo e definitivo o que acontecerá. Deve-se ter em mente que os conhecimentos têm que ser administrados da melhor forma possível a fim de alcançarmos os objetivos propostos. O professor, sob esta visão complexa, está muito mais integrado no contexto do aprendizado do aluno, como uma ação conjunta da equipe.

Estamos trabalhando no sentido de que dentro de alguns anos, profissionais nas mais variadas partes do mundo, possam trabalhar em conjunto para prover um ambiente de ensino qualificado e globalizado. Por outro lado, muito mais alunos podem ser atingidos com esta nova abordagem de ensino.

\section{Considerações Finais}

A evolução das tecnologias de informação e de comunicação induz uma crescente evolução no processo educativo, o que requer estruturas administrativas e pedagógicas dinâmicas e eficazes para que os cursos a distância alcancem sucesso pleno. Entretanto, cabe salientar que esta evolução visível nos cursos a distância também está presente nas outras modalidades de curso. As considerações que foram expostas neste artigo, longe de se tratar de mero modernismo por tecnologias, representam uma alternativa viável para atendimento de uma demanda social que, do modo tradicional de ensino presencial, foge às condições financeiras de infra-estrutura e de pessoal das IFES, não permitindo uma resposta condizente com a necessidade regional.

A gestão adotada num curso influencia diretamente na dinâmica de sua execução e esta deve ser aberta à sociedade, assumindo uma transparência que deixe a comunidade a vontade para perceber o que realmente a Universidade faz e pode fazer por ela. Deve estar fundamentada numa visão sistêmica e estratégica articulando prática, teoria, mercado, política e futuro; medindo em cada curso a eficiência organizacional e o perfil pedagógico. A qualidade do produto da universidade quer seja o profissional por ela formado ou o material científico desenvolvido deve estar a serviço da sociedade, sempre vinculados aos três eixos: ensino, pesquisa e extensão.

Contudo, salientamos que não basta o desenvolvimento de uma boa proposta pedagógica ou que bons materiais instrucionais sejam produzidos para garantir o sucesso de um curso ou programa de EAD. Estas condições são absolutamente necessárias, mas, não são suficientes para propiciar que o aluno possa se engajar num processo de aprendizagem efetivo. A estrutura organizacional voltada para procedimentos que viabilizem a integração dos diversos mecanismos é fundamental para a qualidade e para o sucesso de qualquer proposta que envolva uma formação de qualidade seja em EAD ou não.

O processo de Educação a Distância, como está hoje sendo concebido, é novo e bastante complexo. É necessário que o planejamento seja bem elaborado e que todos os envolvidos neste processo tenham clareza de sua função e suas atribuições peculiares. É preciso que saibam exatamente quais os objetivos a serem alcançados, os métodos que serão aplicados e as tecnologias que podem ser utilizadas. Além disso, quem se 
envolver nesta nova modalidade de ensino, deverá estar preparado e disposto a enfrentar novos desafios constantemente, colaborando para que a demanda de trabalho se torne ainda mais volumosa. Por se tratar de uma modalidade ainda em construção na sociedade brasileira, necessitando de várias adaptações em relação à realidade da região de cada pólo onde o curso foi ou será implantado, o ensino a distância está sendo executado de várias maneiras no território brasileiro. Assim, fica evidente que é difícil chegarmos a um modelo padrão para ser implantado no Brasil.

Como trabalho futuro, pretende-se comparar o modelo de estruturação apresentado com modelos adotados por outras instituições.

\section{Agradecimentos}

Agradecemos à Universidade Federal de Pelotas, à Financiadora de Estudos e Projetos e à Secretaria de Educação a Distância do MEC pelo apoio ao Projeto CLMD.

\section{Referências bibliográficas}

BOF, A. M. Gestão de Sistemas de Educação a Distância. In: ALMEIDA, Maria Elizabeth Bianconcini de.; MORAN, José Manuel (Org.). Integração das tecnologias na educação. Brasília: Ministério da Educação, Seed, 2005. 204 p.

DANDOLINI, G.A., SOUZA, J. A. e SOUZA, A. A. Ensino a Distância: Condições de oferta baseada no uso das TICS nas instituições Federais de Ensino Superior. In: COBENGE 2007. Curitiba.

GRÜTZMANN, T. P.; AFONSO, R. F. da S.; SOUZA, J. A. de; DANDOLINI, G. A. A Tutoria como Auxílio no Ensino de Matemática a Distância. In: XV CONGRESSO DE INICIAÇÃO CIENTÍFICA - UFPEL, 2006, Pelotas. Anais do XV - CIC - UFPEL. Pelotas: UFPEL, 2006. p. 1-5.

HARDY C.; FACHIN, R. Gestão estratégica na universidade brasileira - teoria e ação. Rio Grande do Sul: Universidade UFGRS, 2000.

SOUZA, J. A.; VERGARA-NUNES, E. L.; DANDOLINI, G. A.; BRETTAS, L. A. Curso de Licenciatura em Matemática a Distância: Uma Síntese do Projeto Pedagógico. Renote: Revista Novas Tecnologias na Educação, Porto Alegre, v. 3, n. 1, p. 1-10, 2005.

SOUZA. J. A.; VERGARA-NUNES, E. L.; DANDOLINI, G. A.; BRETTAS, L. A. Busca de um Modelo de Avaliação no Curso de Licenciatura em Matemática a Distância. Renote: Revista Novas Tecnologias na Educação, Porto Alegre, v. 2, n. 2, p. 1-7, 2004.

VERGARA-NUNES , H. L. SOUZA, J. A. e DANDOLINI, G. A Laboratório de Ensino de Matemática a Distância. Renote: Revista Novas Tecnologias na Educação, Porto Alegre, v. 1, n. 1, p. 1-7, 2005. 